\title{
Expression of the Blue-Light Receptor Cryptochrome in the Human Retina
}

\author{
Carol L. Thompson, ${ }^{1}$ Catherine Bowes Rickman, ${ }^{2,3}$ Steven J. Shaw, ${ }^{2}$ Jessica N. Ebright, ${ }^{2}$ \\ Una Kelly, ${ }^{2}$ Aziz Sancar, ${ }^{1}$ and Dennis W. Rickman ${ }^{2,4}$
}

Purpose. To analyze the patterns of expression of the cryptochromes, CRY1 and $C R Y 2$, in the human retina and to correlate expression of these putative blue-light receptors with nonvisual photoreceptor localization.

Methods. CRY1 and CRY2 mRNA expression was analyzed in 4-mm diameter punches of macula and midperipheral human retina by quantitative RT-PCR. CRY2 protein expression was examined by immunohistochemistry in cross sections of human retina, and its subcellular localization was determined by immunoblot analysis of fractionated human retinal extracts.

Results. CRY2 mRNA was 11 times more abundant than CRY1 throughout adult human retina. CRY2 immunoreactivity was detected in most cells in the ganglion cell layer (GCL) and in a subset of cells in the inner nuclear layer (INL) in both the macula and periphery. Immunoperoxidase staining further revealed that CRY2 was localized throughout the cytoplasm of cells in the GCL as well as within nuclei. This intracellular localization of CRY2 was confirmed by immunoblot analysis of fractionated human retinal extracts.

Conclusions. Photopigments governing circadian photoreception have been localized to the inner retina. The relative abundance of CRY2 transcripts, coupled with CRY2 localization to the inner retina, supports a photoreceptive role for CRY2 in human retina. Furthermore, the discovery that CRY2 is also localized within the cytoplasm of some cells in the GCL, suggests it may perform a function separate from its known nuclear role in the transcriptional feedback loop underlying the molecular circadian clock. (Invest Opbthalmol Vis Sci. 2003; 44:4515-4521) DOI:10.1167/iovs.03-0303

$\mathrm{T}$ he retina is the only tissue in mammals that regulates photoreception, both visual and nonvisual. ${ }^{1}$ Nonvisual photoreception encompasses multiple responses to light such as circadian photoentrainment and pupillary light responses, and unlike vision, which is known to be regulated by the rod and cone photoreceptors of the outer retina, these nonvisual

From the ${ }^{1}$ Department of Biochemistry and Biophysics, University of North Carolina School of Medicine, Chapel Hill, North Carolina; and the Departments of ${ }^{2}$ Ophthalmology, ${ }^{3}$ Cell Biology, and ${ }^{4}$ Neurobiology, Duke University Medical Center, Durham, North Carolina.

Supported by National Eye Institute R01-EY11286 (CBR), R01EY11389 (DWR), and P30-EY05722 (Duke University Eye Center); Grant R01-GM31082 from the National Institute of General Medical Sciences (AS); and a Career Development Award from Research to Prevent Blindness (CBR)

Submitted for publication March 25, 2003; revised May 31, 2003; accepted June 5, 2003

Disclosure: C.L. Thompson, None; C.B. Rickman, None; S.J. Shaw, None; J.N. Ebright, None; U. Kelly, None; A. Sancar, None; D.W. Rickman, None

The publication costs of this article were defrayed in part by page charge payment. This article must therefore be marked "advertisement" in accordance with 18 U.S.C. $\$ 1734$ solely to indicate this fact

Corresponding author: Dennis W. Rickman, Department of Ophthalmology, Duke University Medical Center, Erwin Road, Box 3802, Durham, NC 27710; dennis.rickman@duke.edu. irradiance detection tasks occur through poorly understood photoreceptive pathways. In the $r d$ mouse with retinal degeneration caused by a mutation in the $\beta$-subunit of cGMP phosphodiesterase, ${ }^{2}$ complete rod photoreceptor cell loss occurs by 3 weeks of age followed by degeneration of cone photoreceptors by 3 months. ${ }^{3}$ However, these mice retain robust circadian responses to light, ${ }^{4,5}$ indicative of the existence of a novel photopigment in the inner retina. Candidate photoreceptive molecules include a novel opsin, melanopsin, and a separate class of blue-light photoreceptors, cryptochromes.

Melanopsin is a recently discovered opsin expressed in the inner retina of the mouse and human. In the mouse retina, melanopsin is restricted to a small subset of cells in the ganglion cell layer $(\mathrm{GCL})^{6}$ that are directly photoresponsive. ${ }^{7,8}$ However, mice without melanopsin still have robust circadian photoresponses $^{9,10}$ and pupillary light responses. ${ }^{11}$ Therefore, because the requirement for melanopsin-expressing, photosensitive ganglion cells to circadian photoreception in particular and nonvisual photoreception in general remains speculative, the existence of an additional photoreceptive molecule is highly probable.

Cryptochromes, in contrast, represent an entirely different class of photopigments, belonging to the photolyase blue-light receptor family. Unlike the retinaldehyde-based opsins, cryptochromes use two light-absorbing cofactors: flavin adenine dinucleotide and methenyltetrahydrofolate. ${ }^{12}$ In human and in mouse, there are two cryptochromes: CRY1 and CRY2. ${ }^{13}$ In cry $1^{-/-}$and $c r y 2^{-/-}$single knockout mice, circadian photoresponses are abnormal, indicating that these proteins may indeed be circadian photopigments. ${ }^{14,15}$ However, these proteins are also intimately involved in intrinsic circadian clock function, introducing an element of complexity when interpreting the dramatic reduction in photoresponsiveness we have observed in the double-mutant $\operatorname{cry} 1^{-1-} \operatorname{cry} 2^{-1-}$ mice. ${ }^{15,16}$ In situ localization of cryptochrome mRNAs in the mouse suggests that the two cryptochromes are not completely redundant. ${ }^{17}$ These studies support a predominantly circadian clock regulatory function for $c r y 1$, which is highly expressed in the mouse suprachiasmatic nucleus (SCN), and a predominantly photoreceptive function for $\operatorname{cry} 2$, which is highly expressed in the mouse retina. ${ }^{17}$

Evidence for cryptochromes as circadian photopigments also exists in other species, including Drosophila and zebrafish. In Drosophila, for example, the cryptochrome mutation $c r y^{\mathrm{b}}$, which affects flavin binding in the sole fruit fly cryptochrome, results in loss of certain light-regulated types of behavior, including phase-shifting by light. ${ }^{18,19}$ In zebrafish, where heart and kidney (and even a cell line isolated from the zebrafish embryo) are as responsive to light as retina, ${ }^{20}$ the nonvisual photoresponsive cells express at least four cryptochromes and display an action spectrum consistent with peak absorption of cryptochrome. ${ }^{21}$ In addition, cryptochrome plays an important role in mammalian pupillary constriction. Recent data indicate that the pupillary responses of mice without rods, cones, and cryptochromes are only $5 \%$ as sensitive to blue light as those of mice lacking only rods and cones. ${ }^{22}$ 
TABLE 1. Information on Human Donors Used for the Studies

\begin{tabular}{llll}
\hline \multicolumn{1}{c}{ Experiment } & Age, Sex & $\begin{array}{c}\text { Time of } \\
\text { Death }\end{array}$ & \multicolumn{1}{c}{ Cause of Death } \\
\hline Real-time RT-PCR & 60 YO F & $21: 15$ & Breast cancer \\
Real-time RT-PCR & 43 YO M & $18: 40$ & Anoxic brain injury \\
Real-time RT-PCR & 74 YO F & $14: 10$ & Acute renal failure \\
Real-time RT-PCR & 73 YO M & $17: 04$ & Lung cancer \\
Real-time RT-PCR & 68 YO F & $13: 50$ & Leukemia \\
Real-time RT-PCR & 56 YO F & $01: 55$ & Breast cancer \\
Real-time RT-PCR & 32 YO F & $11: 35$ & End-stage renal disease \\
Immnohistochemistry & 47 YO F & $19: 09$ & Cervical cancer \\
Biochemistry & 59 YO M & $07: 40$ & Myocardial infarction \\
Biochemistry & 58 YO M & $11: 45$ & Cervical cancer \\
\hline
\end{tabular}

The accumulating genetic evidence supporting a photoreceptive function for cryptochromes in the mouse and other species suggests cryptochromes could function as photoreceptors in humans. There has been no analysis of cryptochrome expression or localization in human retina to date, and even in the mouse, cryptochrome expression in the retina has not yet been examined in detail. Therefore we examined mRNA expression profiles of $C R Y 1$ and $C R Y 2$, as well as CRY2 protein expression in the human retina, to gain further insight into the functions of these proteins.

\section{Materials ANd Methods}

\section{Real-Time Quantitative RT-PCR}

Human donor eyes were obtained within 4 hours of death from the North Carolina Eye Bank (Table 1). Total retinal RNA was isolated from 4-mm trephine punches of two separate regions of neural retina, macula, and midperipheral retina, DNase treated, and quantitated using an RNA quantitation reagent (RiboGreen; Molecular Probes, Eugene, OR), as described previously. ${ }^{23}$ Total human placental RNA was purchased from BD Biosciences-Clontech (Palo Alto, CA). First-strand cDNAs were synthesized from equal amounts of total RNA $(1 \mu \mathrm{g} /$ reaction) with a cDNA synthesis kit (iScript) as described by the manufacturer (Bio-Rad, Hercules, CA).

Real-time quantitation of $C R Y 1$ and $C R Y 2$ mRNAs normalized to an endogenous reference, $\beta$-actin $(A C T B)$, was performed using the iCycler iQ detection system (Bio-Rad) as previously described. ${ }^{23}$ Briefly, a PCR master mix (iQ Supermix, Bio-Rad) for each gene-specific primer (GSP) pair (Table 2) with each cDNA template was prepared. Reactions consisted of $1 \mu \mathrm{L}$ of template cDNA/20- $\mu \mathrm{L}$ reaction, $2 \times$ PCR master mix, $10 \mathrm{nM}$ fluorescein calibration dye (Bio-Rad), $1 \mu \mathrm{L}$ of a 1:1500 dilution of 10,000 $\times$ nucleic acid dye (SYBR Green 1; Molecular Probes) and $500 \mathrm{nM}$ of each GSP pair. Duplicate reactions were amplified using the following PCR amplification protocol: $95^{\circ} \mathrm{C}$ for 2 minutes followed by 50 cycles of $95^{\circ} \mathrm{C}$ for 15 seconds, $60^{\circ} \mathrm{C}$ for 15 seconds, and $72^{\circ} \mathrm{C}$ for 15 seconds. The increase in fluorescence was measured in real time during the extension step, and melt curves were obtained immediately after amplification by increasing temperature in $0.4^{\circ} \mathrm{C}$ increments from $65^{\circ} \mathrm{C}$ for 85 cycles of 10 seconds each and analyzed using the analysis software that accompanied the system
(iCycler; Bio-Rad). Amplification of a single PCR product per primer pair was verified by the presence of a single melting temperature peak on each melt curve and by analysis on a $4.5 \%$ acryl agarose gel (DNA Technologies Inc., Gaithersburg, $\mathrm{MD})$. The threshold cycle $\left(\mathrm{C}_{\mathrm{T}}\right)$ was the cycle at which the amount of amplified sample reached a fixed threshold of 100 relative fluorescence units (RFU). The fold difference between $C R Y 1$ or $C R Y 2$ normalized to the endogenous control gene (ACTB) and relative to $C R Y 1$ in peripheral retina was calculated by the comparative $C_{\mathrm{T}}$ method $\left(2^{-\Delta \Delta \mathrm{CT}}\right)$ as described by the manufacturer (Prism 7700 Sequence Detection System; Applied Biosystems, Inc., Foster City, CA). We demonstrated equal PCR amplification efficiencies of each target cDNA sequence in the peripheral retina cDNA sample on a PCR standard curve with a correlation coefficient of 0.999 and a PCR amplification efficiency of $94.6 \%$ (data not shown).

\section{Immunohistochemistry}

Human donor eyes were preserved within 4 hours of death by immersion in $4 \%$ paraformaldehyde for 6 hours after removal of the cornea and lens (Table 1). Eyes were stored at $4^{\circ} \mathrm{C}$ in $1 \%$ paraformaldehyde until use. Five-millimeter trephine punches of the macula and midperipheral retina were obtained, cryoprotected, and cryosectioned. Cryosections $(10 \mu \mathrm{m})$ were washed in several changes of PBS. All steps were performed at room temperature unless otherwise indicated. Tissue sections were incubated in $0.02 \mathrm{mg} / \mathrm{mL}$ affinity-purified CRY2 antibody (ADI, San Antonio, TX) in $0.1 \mathrm{M}$ PBS $+0.5 \%$ Triton X-100+10\% normal goat serum (NGS) for 12 to 16 hours at $4{ }^{\circ} \mathrm{C}$. Sections were then washed in PBS (three times, 10 minutes each) and incubated in a goat anti-rabbit IgG antibody conjugated to carboxymethylindocyanine (Cy3; Jackson ImmunoResearch, West Grove, PA) at 1:100 to 1:200 for 1 hour. Some sections were counterstained with the nuclear stain $4^{\prime}$, 6 '-diamidino-2-phenylindole hydrochloride (DAPI).

Alternatively, slides were pretreated in $\mathrm{H}_{2} \mathrm{O}_{2}(150 \mu \mathrm{L} / 100 \mathrm{~mL})$ and thoroughly washed in PBS before incubation in CRY2 antibody. Slides were then washed in PBS and transferred to goat anti-rabbit biotinylated secondary antibody (1:50; Jackson ImmunoResearch) for 2 hours. After incubation and washing in PBS, sections were incubated in an avidin-biotin-peroxidase mixture (Vectastain $\mathrm{ABC}$ kit; Vector Laboratories, Burlingame, CA) for 1 hour and in 3,3'-diaminobenzidine tetrahydrochloride (DAB; Sigma-Aldrich, St. Louis, MO) for 10 minutes followed by brief treatment with $\mathrm{DAB}$ and $0.03 \% \mathrm{H}_{2} \mathrm{O}_{2}$. Slides were washed in PBS, coverslipped with a glycerin-PBS mixture, and analyzed with a microscope equipped either with epifluorescence (Optiphot; Nikon, Tokyo, Japan) or with differential interference contrast optics. Antibody specificity was demonstrated either by eliminating primary antibody or by preadsorption of antibody with $0.1 \mathrm{mg} / \mathrm{mL}$ CRY2 peptide (ADI) overnight at $4^{\circ} \mathrm{C}$ before incubation.

\section{Antibody for Immunoblot Analysis}

A rabbit polyclonal peptide CRY2 antibody was generated against a synthetic peptide with the sequence CGGSSGPASPKRKLEAAEE (italic region corresponds to residues 554-568 of human CRY2, or 553-567 of mouse Cry2) conjugated to keyhole limpet hemocyanin (KLH). Rabbit immunizations were performed in the presence of Freund's adjuvant by Covance Research Products, Inc. (Denver, PA), using their standard 118-day protocol. This antibody was purified from antiserum collected

TABLE 2. Primers Used for Real-Time Quantitative RT-PCR

\begin{tabular}{|c|c|c|c|c|c|}
\hline Gene & Acc. No.* & $5^{\prime}$ Primer & $3^{\prime}$ Primer & Base Pairst & Amplicon (bp) $\ddagger$ \\
\hline$C R Y 1$ & D83702 & CTCCATGGGCACTGGTCTCAGTG & TCСССАССАATTTCAGCTGCAAC & 2251-2391† & $141(\mathrm{bp}) \ddagger$ \\
\hline CRY2 & $\mathrm{AB} 014558$ & CCAAGAGGGAAGGGCAGGGTAGAG & AGGATTTGAGGCACTGTTCCGAGG & $3840-3964$ & $125(\mathrm{bp}) \ddagger$ \\
\hline АСТВ & XM_037237 & CCTCGCCTTTGCCGATCCG & GCCGGAGCCGTTTGTCGACG & $13-106$ & $94(\mathrm{bp}) \neq$ \\
\hline
\end{tabular}

* GenBank accession numbers; provided by the National Institutes of Health.

$\dagger$ Amplified region is indicated, using numbers from the GenBank file.

$\ddagger$ Size of the amplified product 
after three booster shots and was affinity purified with a recombinant Cry2 protein crosslinked to agarose resin (AminoLink; Pierce, Rockford, IL) according to the manufacturer's instructions. The recombinant protein used for purification was a fragment of the mouse Cry $2 \mathrm{C}$ terminus (residues 373-592) fused to the $\mathrm{C}$ terminus of glutathione-Stransferase (GST), which was purified on glutathione Sepharose (Pharmacia, Piscataway, NJ) according to the manufacturer's instructions. Final antibody concentration was approximately $0.2 \mathrm{mg} / \mathrm{mL}$.

\section{Cell Lysates}

Cell lysates were prepared from a stably transfected 293T cell line that overexpresses recombinant human CRY2, using the construct pSÖ2002 (which expresses hCRY2 with Myc, His, and Flag tags at the carboxyl terminus ${ }^{24}$ ); transfected by calcium-phosphate precipitation $^{25}$; and selected with Zeocin (Invitrogen). Briefly, stably transfected or untransfected 293T cells were grown in DMEM (InvitrogenGibco) supplemented with $10 \%$ fetal bovine serum and after washing with PBS, cells were collected and homogenized in ice-cold $1 \mathrm{~mL}$ lysis buffer (50 mM Tris [pH 8.0], $150 \mathrm{mM} \mathrm{NaCl}, 0.02 \%$ sodium azide, $1 \%$ $\mathrm{NP} 40,1 \mu \mathrm{g} / \mathrm{mL}$ leupeptin, $1 \mu \mathrm{g} / \mathrm{mL}$ pepstatin A, $10 \mathrm{mM}$ iodoacetamide, $1 \mathrm{mM}$ phenylmethylsulfonyl fluoride [PMSF]) yielding cell lysates at final protein concentrations of 2.5 and $3.6 \mathrm{mg} / \mathrm{mL}$, respectively.

Eyes were obtained from wild-type mice with a mixed background of $129 / \mathrm{Sv} \times \mathrm{C} 57 \mathrm{BL} / 6 \times \mathrm{C} 3 \mathrm{H} / \mathrm{HeJ}$, and $r d / r d$ (retinal degeneration allele) cry $1^{-/-}$cry $^{-/-}$(lacking both cryptochromes) triple-mutant mice with the same background, ${ }^{16}$ in accordance with the ARVO Statement for the Use of Animals in Ophthalmic and Vision Research. Retinal lysates were prepared by homogenization of four eyes of each genotype in $1 \mathrm{~mL}$ lysis buffer.

\section{Cell Fractionation}

Human retina obtained from a fresh donor eye, in accordance with the Declaration of Helsinki, was homogenized in $1 \mathrm{~mL}$ hypotonic lysis buffer $(5 \mathrm{mM} N$-ethylmaleimide, $10 \mathrm{mM}$ EDTA, protease inhibitor cocktail tablet; Complete Mini, EDTA-free; Roche Diagnostics, Indianapolis, IN) on ice in a prechilled 2-mL homogenizer (Dounce, Bellco Glass Co, Vineland, NJ). The recovered retinal homogenate was placed in a $1.5-\mathrm{mL}$ microfuge tube, and nuclei were pelleted by centrifugation for 30 seconds at $800 \mathrm{~g}$. The entire homogenate, less approximately 25 $\mu \mathrm{L}$ (nuclear fraction), was layered over $250 \mu \mathrm{L} 2 \mathrm{M}$ sucrose in a $2.0-\mathrm{mL}$ microfuge tube and centrifuged for 1 hour at $16,000 \mathrm{~g}$ and $4^{\circ} \mathrm{C}$. The top layer, or cytosolic fraction, was carefully aspirated with a pipette and transferred to a $1.5-\mathrm{mL}$ tube, leaving behind the membranes at the sucrose interface. The cytosol was centrifuged for 15 minutes at $30,000 \mathrm{~g}$ to clear any remaining insoluble material or residual membranes.

\section{Immunoblot Analysis}

Cell lysates were denatured in SDS reducing buffer, separated on a $10 \%$ polyacrylamide gel, and transferred to a polyvinylidene difluoride (PVDF) membrane (Bio-Rad). After the membrane was blocked for 1 hour in 10\% fat-free milk and washed in TBST (three times, 10 minutes each) it was incubated with the CRY2 peptide antibody at 1:3000 dilution $(0.067 \mu \mathrm{g} / \mathrm{mL})$ overnight at $4{ }^{\circ} \mathrm{C}$. The blot was washed again in TBST (three times, 10 minutes each), followed by incubation with a 1:5000 dilution of peroxidase-conjugated donkey anti-rabbit IgG (Jackson ImmunoResearch) for 1 hour at room temperature. After three more washes in TBST, chemiluminescence reagent (ECL plus; Amersham Biosciences, Arlington Heights, IL) was added for 5 minutes and the Western blot was exposed to film (Biomax MRFilm; Eastman Kodak, Rochester, NY).

\section{Peptide Adsorption}

The PVDF membrane used previously for CRY2 detection in cell lysates was stripped for 30 minutes with $50 \mathrm{mM}$ Tris (pH 6.5), $2 \%$ SDS, and 50 $\mathrm{mM} \beta$-mercaptoethanol at $65^{\circ} \mathrm{C}$. The membrane was then incubated in

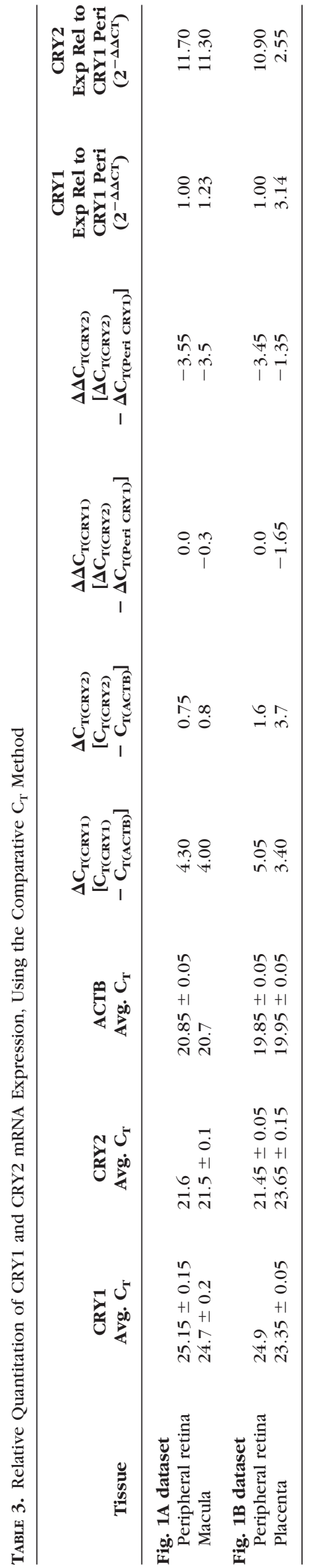


A

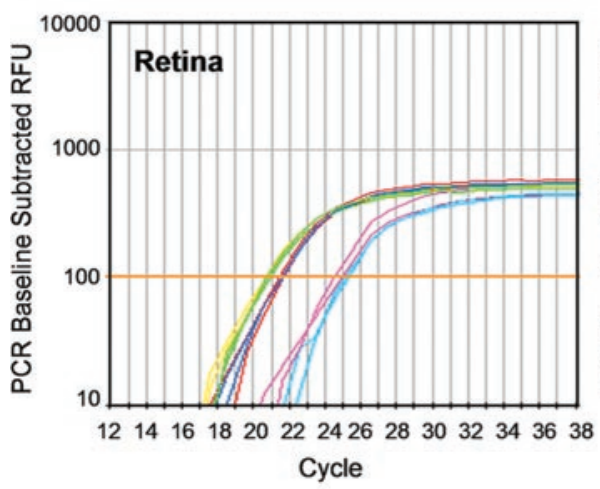

Gene
ACTB
ACTB
ACTB
ACTB
CRY1
CRY1
CRY1
CRY1
CRY2
CRY2
CRY2
CRY2
B

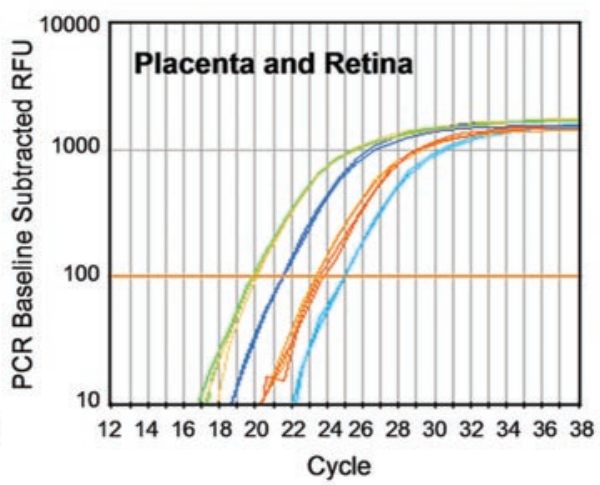

\begin{tabular}{|c|c|c|c|c|c|}
\hline Region & $c_{T}$ & & Gene & Tissue & $c_{T}$ \\
\hline Macula & 20.7 & & ACTB & Retina & 19.9 \\
\hline Macula & 20.7 & & ACTB & Retina & 19.8 \\
\hline Periphery & 20.9 & - & ACTB & Placenta & 19.9 \\
\hline Periphery & 20.8 & & ACTB & Placenta & 20 \\
\hline Macula & 24.9 & & CRY1 & Retina & 24.9 \\
\hline Macula & 24.5 & & CRY1 & Retina & 24.9 \\
\hline Periphery & 25.0 & - & CRY1 & Placenta & 23.3 \\
\hline Periphery & 25.3 & - & CRY1 & Placenta & 23.4 \\
\hline Macula & 21.6 & & CRY2 & Retina & 21.4 \\
\hline Macula & 21.4 & & CRY2 & Retina & 21.5 \\
\hline Periphery & 21.6 & & CRY2 & Placenta & 23.5 \\
\hline Periphery & 21.6 & 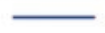 & CRY2 & Placenta & 23.8 \\
\hline
\end{tabular}

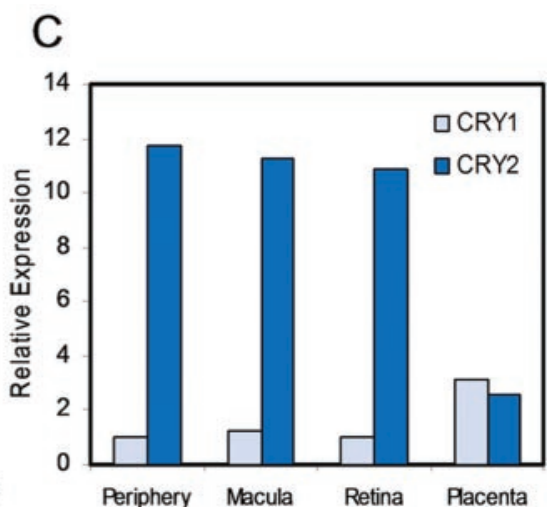

Periphery Macula Retina Placenta

FIGURE 1. Quantitation of the relative levels of $C R Y 1$ and $C R Y 2$ mRNA in the human retina and placenta. Logarithmic fluorescence history versus cycle number of target genes $C R Y 1, C R Y 2$, and reference gene $A C T B$ in (A) macula and peripheral retina and (B) peripheral retina and placenta. Trace colors for each sample (duplicate reactions) are shown below the graphs. (C) Summary of gene expression relative to CRY1 expression in peripheral retina.

a primary CRY2 antibody solution $(0.067 \mu \mathrm{g} / \mathrm{mL}$, final concentration) that had been preadsorbed by overnight incubation in a $15-\mathrm{mL}$ solution of CRY2-specific peptide (CGGSSGPASPKRKLEAAEE) at a final peptide concentration of $13.3 \mu \mathrm{g} / \mathrm{mL}$.

\section{Results}

\section{Relative Gene Expression of $C R Y 1$ and $C R Y 2$ in Retina}

Previous studies in the mouse have shown that mRNA expression of both cry 1 and cry 2 is restricted to the GCL and inner nuclear layer (INL) of the retina and that there is qualitatively more $c r y 2$ mRNA than cry $1 .{ }^{17}$ To determine whether there is a comparable expression profile of the cryptochrome genes in the human retina, we quantitated $C R Y 1$ and $C R Y 2$ expression by real-time RT-PCR in 4-mm punches of human tissue taken from either the macula or midperipheral retina (Table 3, Fig. 1A). Strikingly, levels of $C R Y 2$ mRNAs were approximately 11 times higher than that of $C R Y 1$ in both macula and peripheral retina (Table 3, Figs. 1A, 1C). In contrast to the expression levels of $C R Y 2$ versus $C R Y 1$ transcripts observed in retina, in the nonphotoreceptive tissue (placenta), levels of $C R Y 2 \mathrm{mRNA}$ were slightly lower than $C R Y 1$, and only three times higher than that of $C R Y 1$ in peripheral retina (Table 3, Figs. 1B, 1C).

\section{Immunohistochemical Analysis of CRY2 Expression}

To establish CRY2 as a nonvisual photoreceptive molecule in humans requires that its cellular distribution matches the known localization of the circadian photoreceptor to the inner retina. We therefore analyzed the expression of CRY2 by im- munohistochemistry on transverse sections of normal adult human retina.

In both the macula and peripheral retina, CRY2 immunoreactivity was present in numerous cells throughout the GCL (Fig. 2). Some lightly immunostained cells were also present in the proximal layers of the INL. In addition, occasional labeled processes were observed in the inner plexiform (IPL) and nerve fiber (NFL) layers. In the peripheral retina, robust CRY2 immunoreactivity appeared to be cytoplasmic, but a lower level of nuclear labeling could not be ruled out, especially in heavily stained cells. However, in the macula, there was clear evidence for nuclear labeling. In fluorescence studies, sections double labeled with anti-CRY2 and the nuclear stain DAPI revealed that CRY2 immunoreactivity was present in most cells in the GCL and that CRY2 localization is primarily cytoplasmic. Finally, omission of the primary antibody, or peptide adsorption with the epitope-containing CRY2 peptide, eliminated all staining, whereas adsorption with a nonspecific peptide did not (data not shown), substantiating the specificity of CRY2 immunostaining.

\section{Cytoplasmic Localization of CRY2}

The nuclear, light-independent function of cryptochrome in the transcriptional feedback loop underlying circadian rhythm generation is known, and expression of cryptochromes in mouse brain tissue and in cultured cells has been shown to be primarily nuclear. However, the apparent localization of CRY2 immunoreactivity to the cytoplasm of retinal ganglion cells could be indicative of a cell-specific, compartment-specific function for CRY2. To confirm this localization, we fractionated human retinal lysate into cytoplasmic and nuclear frac- 

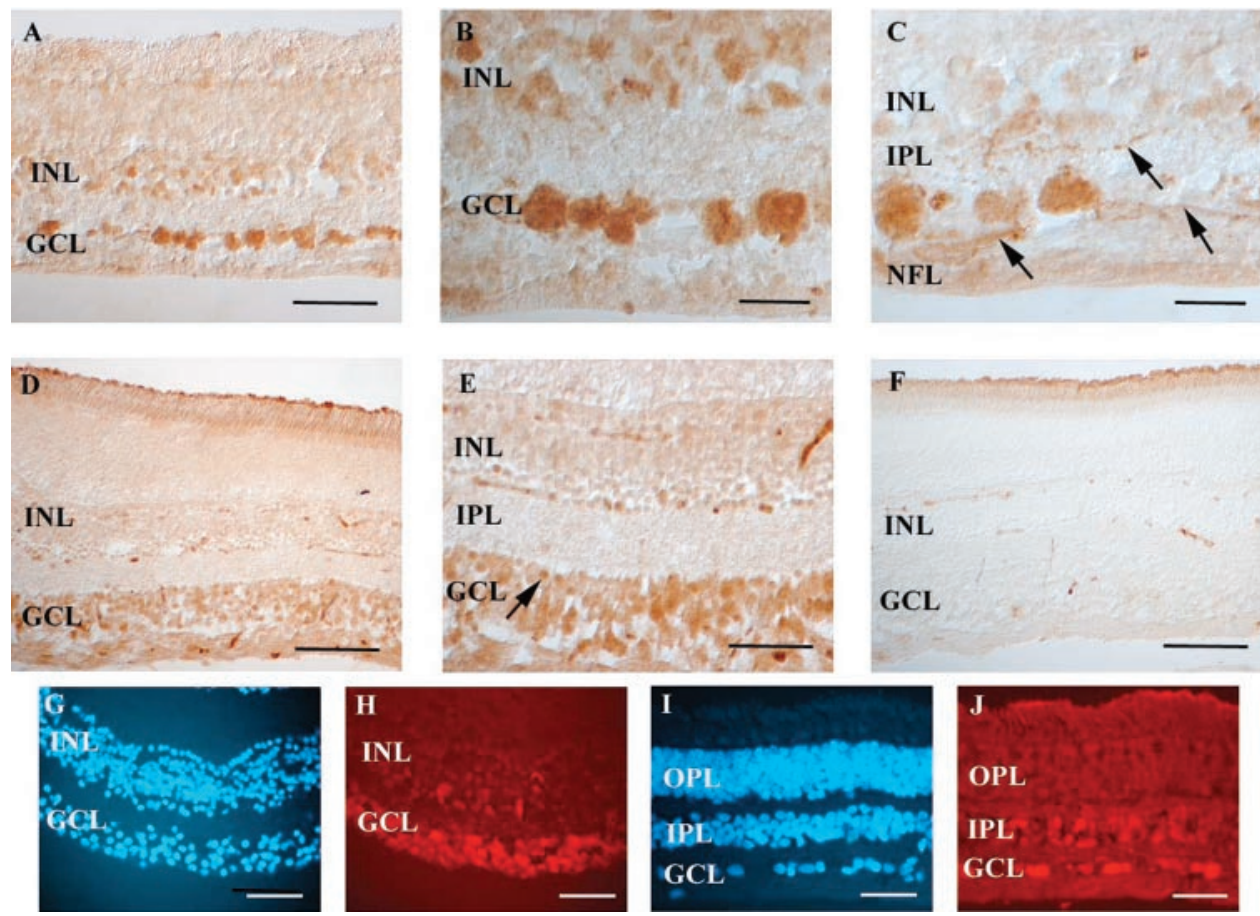

FIGURE 2. CRY2 immunoreactivity in the human retina. (A-C) Peripheral retina. (A) CRY2 immunoreactivity was present throughout the cytoplasm of cells primarily located in the GCL. Occasional, lightly stained cells were also present in the INL. (B) Higher magnification of (A). (C) In addition to labeled somata, some immunostained processes were observed in the proximal IPL and in the NFL (arrows). (D-F) Macula. (D) In the macula CRY2 immunoreactivity was present in cells throughout the GCL. (E) Many cells in the GCL displayed strong CRY2 immunoreactivity throughout the cytoplasm. However, in some cells labeling was restricted to the nucleus (arrow). (F) CRY2 immunostaining was eliminated in sections incubated with CRY2 antibody preadsorbed with an epitope-containing peptide. (G-J) Doublelabel histochemistry showing the distribution of CRY2 immunoreactivity compared with the overall cellular density, as revealed by staining with the nuclear marker, DAPI (G, H: macula; I, J: peripheral retina). Scale bars: (A, D-J) $50 \mu \mathrm{m}$; (B, C) $25 \mu \mathrm{m}$.

tions and determined the subcellular localization of CRY2 protein by Western blot analysis.

For immunoblot analysis, we used an antibody separate from that used for immunostaining. This antibody, which recognizes the recombinant CRY2 control (Fig. 3A, lane 2), recognized a band in the cytoplasmic fraction of human retinal lysate (Fig. 3B, lane 1) that comigrated with the mouse Cry2 (mCry2) band (Fig. 3B, lane 2), consistent with the fact that the human CRY2 sequence is only 1 amino acid longer than the mCry2 sequence. The presumptive CRY2 band was eliminated by peptide adsorption of the antibody (Fig. 3B, right panel). Comparison of nuclear and cytoplasmic extracts demonstrated the existence of CRY2 in both subcellular compartments (Fig. 3C).

\section{Discussion}

Mammalian circadian photoreception has been localized to the inner retina, but the responsible photopigment is unknown. Because cryptochrome is an excellent candidate as a photopigment regulating circadian photoentrainment and other nonvisual photoresponses such as the pupillary light response, we analyzed the pattern of cryptochrome expression in the human retina.

In previous studies we determined that $c r y 2$ mRNA, and to a lesser extent cry1, were expressed in the INL and GCL of the mouse retina, with some expression also observed in photoreceptor nuclei. ${ }^{17}$ These semiquantitative data were obtained by in situ hybridization and did not reveal relative differences between cry 1 and cry 2 expression. Recombinant mouse cryptochromes tagged with green fluorescent protein (GFP) or hemagglutinin and overexpressed in cell culture exhibit a nuclear localization $^{14,26,27}$; however, these conditions may not accurately reflect cryptochrome expression in situ. Immunocytochemical data have been reported for mouse cryptochromes in the SCN, where they are primarily nuclear, ${ }^{27}$ but similar studies have not been performed in the retina. Indeed, the proposed pleomorphic roles for cryptochromes ${ }^{16,28}-\mathrm{a}$ circadian clock function in the SCN and a photoreceptive function in the eye-suggest that either cryptochrome intracellular localization or downstream targets could be different between these two tissues to allow distinct functions.

In this study, we examined the distribution of CRY1 mRNA and CRY2 mRNA and protein and found that CRY2 is the primary cryptochrome expressed in human retina. In addition, we report for the first time that a substantial portion of CRY2 protein exists in the cytoplasm of the human retina, as shown both by the immunostaining and by immunoblot of fractionated retinal lysates. In our analysis of subcellular localization, we used two different antibodies against CRY2 in two different assays, and both confirmed cytoplasmic localization of CRY2. The relative paucity of the $C R Y 1$ transcript in retina may explain, in part, why we were unable to detect CRY1 protein by immunohistochemical methods (data not shown). These data correlate well with the hypothesis that cryptochromes perform partially overlapping functions, in which CRY1 is an essential component of the molecular clock and CRY2 functions predominantly as a photoreceptor. This is also supported 


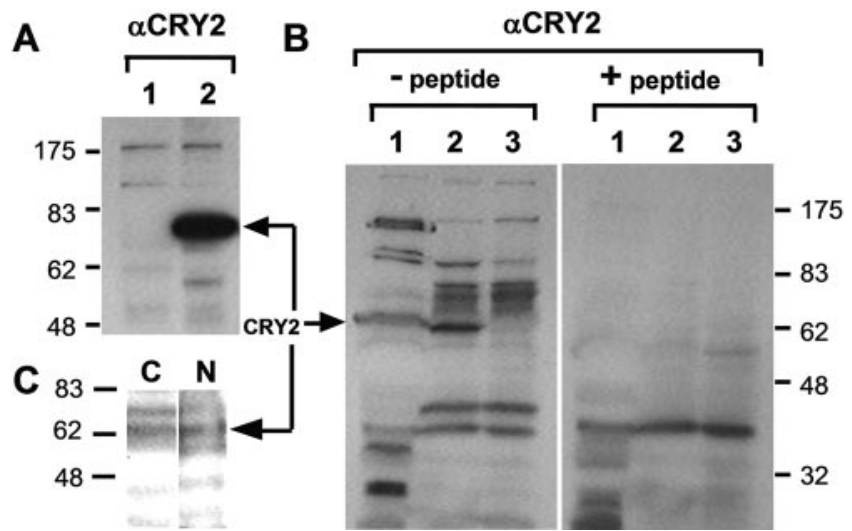

FiguRE 3. Characterization of CRY2 antibody and subcellular localization of CRY2 protein. (A) Recognition of the CRY2 band by a CRY2 anti-peptide antibody in an extract from a stably transfected 293T cell line overexpressing recombinant tagged CRY2 (lane 2) is shown in comparison to an untransfected 293T cell extract (lane 1). Note that the size of the recombinant protein $(73 \mathrm{kDa})$ was larger than endogenous CRY2 (65 kDa), due to addition of Myc, His, and Flag tags. (B) Recognition and peptide adsorption of CRY2 band. Lane 1: human retinal lysate, cytoplasmic fraction; lane 2: wild-type mouse extract from whole eye; lane 3: mouse whole eye extract without cryptochromes $\left(\mathrm{rd} / \mathrm{rd} \mathrm{cry} 1^{-/-} \mathrm{cry} 2^{-/-}\right)$. Left: without peptide; right: adsorption with excess peptide. Note that migration of the CRY2 band (left, lane 1) was somewhat distorted by the presence of a large amount of an unknown protein migrating with the 48 -kDa standard. (C) Comparison of cytoplasmic (C) and nuclear $(\mathrm{N})$ fractions of human retinal lysate. Amount of fractionated lysate loaded in cytoplasmic lane was $3.7 \%$ of one retina versus the amount in the nuclear lane, which was from one whole retina (i.e., ratio of $\mathrm{C}$ to $\mathrm{N}$ lysates loaded was 1:27). Arrows: position of CRY2 bands.

by studies demonstrating that mice with only a single cry 1 allele [out of four cry gene alleles (two cry 1; two cry 2)] have sufficient clock function to maintain circadian rhythmicity in constant darkness, but mice with a single cry 2 allele do not. ${ }^{29}$

Because the cryptochromes are integral components of the circadian clock, which regulates daily oscillation in mRNA and protein abundance of both circadian clock genes and output genes, the time of day at which human donor eyes were harvested could affect quantitation of cryptochrome transcripts. However, in the mouse, neither cry 1 nor cry 2 mRNA $^{17}$ nor protein expression (Selby CP, Sancar A, unpublished observations, 1999) oscillates to a significant extent in retina. Therefore, the quantitative PCR analysis of mRNA levels in the human retina is unlikely to be affected by time of death of the human donors.

The retinas of mammals, Xenopus, and chicken are known to possess endogenous circadian pacemakers, and in Xenopus this clock has been roughly localized to photoreceptor nuclei in the outer retina. ${ }^{30}$ Presumably, if CRY1 is primarily responsible for circadian clock function, it should be expressed in photoreceptor nuclei. Supporting evidence comes from studies in the chicken, in which Cry 1 mRNA is highly expressed in photoreceptor nuclei and in the GCL. ${ }^{31}$ However, the finding that human CRY2 is highly expressed at the mRNA level in the retina, and particularly at the protein level in the cytoplasm of ganglion cells, argues for a function for CRY2 not associated with circadian rhythm maintenance in these cells. Furthermore, the detection of CRY2 in the cytoplasm of retinal ganglion cells suggests that phototransduction occurs outside the nucleus, if this is the nonvisual photoreceptive molecule in humans. Collectively, these studies, coupled with recent data suggesting that the other candidate photopigment melanopsin is in fact not required for robust circadian photoreception and phototransduction, ${ }^{9}$ make the photoreceptive function of cryptochromes, in particular CRY2, in the human retina more compelling.

\section{Acknowledgments}

The authors thank Jeff Smith for help with the real-time quantitation, Katarina Boon for insightful comments, Sezgin Özgür for the stably transfected cell line expressing human CRY2 protein, and Lee Chenier of the North Carolina Eye Bank for assistance.

\section{References}

1. Wee R, Castrucci AM, Provencio I, Gan L, Van Gelder RN. Loss of photic entrainment and altered free-running circadian rhythms in matb5-/- mice. J Neurosci. 2002;22:10427-10433.

2. Bowes C, Li T, Danciger M, Baxter LC, Applebury ML, Farber DB. Retinal degeneration in the rd mouse is caused by a defect in the beta subunit of rod cGMP-phosphodiesterase. Nature. 1990;347: 677-680.

3. Carter-Dawson LD, LaVail MM, Sidman RL. Differential effect of the $r d$ mutation on rods and cones in the mouse retina. Invest $O p b$ thalmol Vis Sci. 1978;17:489-498.

4. Foster RG, Provencio I, Hudson D, Fiske S, De Grip W, Menaker M. Circadian photoreception in the retinally degenerate mouse ( $r d$ / rd). J Comp Pbysiol [A]. 1991;169:39-50.

5. Yoshimura T, Ebihara S. Decline of circadian photosensitivity associated with retinal degeneration in CBA/J-rd/rd mice. Brain Res. 1998;779:188-193.

6. Provencio I, Rodriguez IR, Jiang G, Hayes WP, Moreira EF, Rollag MD. A novel human opsin in the inner retina. J Neurosci. 2000; 20:600-605.

7. Berson DM, Dunn FA, Takao M. Phototransduction by retinal ganglion cells that set the circadian clock. Science. 2002;95:10701073.

8. Hattar S, Liao H, Takao M, Berson DM, Yau K. Melanopsin-containing retinal ganglion cells: architecture, projections, and intrinsic photosensitivity. Science. 2002;295:1065-1070.

9. Ruby NF, Brennan TJ, Xie X, et al. Role of melanopsin in circadian responses to light. Science. 2002;298:2211-2213.

10. Panda S, Sato TK, Castrucci AM, et al. Melanopsin (Opn4) requirement for normal light-induced circadian phase shifting. Science. 2002;298:2213-2216.

11. Lucas RJ, Hattar S, Takao M, Berson DM, Foster RG, Yau K-W. Diminished pupillary light reflex at high irradiances in melanopsinknockout mice. Science 2003;299:245-247.

12. Sancar A. Cryptochrome: the second photoactive pigment in the eye and its role in circadian photoreception. Annu Rev Biochem. 2000;69:31-67.

13. Hsu DS, Zhao X, Zhao S, et al. Putative human blue-light photoreceptors hCRY1 and hCRY2 are flavoproteins. Biochemistry. 1996; 35:13871-13877.

14. Thresher RJ, Vitaterna MH, Miyamoto Y, et al. Role of mouse cryptochrome blue-light photoreceptor in circadian photoresponses. Science. 1998;282:1490-1494.

15. Vitaterna MH, Selby CP, Todo $\mathrm{T}$, et al. Differential regulation of mammalian Period genes and circadian rhythmicity by cryptochromes 1 and 2. Proc Natl Acad Sci USA. 1999;96:12114-12119.

16. Selby CP, Thompson CL, Schmitz TM, Van Gelder RN, Sancar A. Functional redundancy of cryptochromes and classical photoreceptors for nonvisual ocular photoreception in mice. Proc Natl Acad Sci USA. 2000;97:14697-14702.

17. Miyamoto Y, Sancar A. Vitamin B2-based blue-light photoreceptors in the retinohypothalamic tracts as the photoactive pigments for setting the circadian clock in mammals. Proc Natl Acad Sci USA. 1998;95:6097-6102.

18. Stanewsky R, Kaneko M, Emery P, et al. The cry ${ }^{\mathrm{b}}$ mutation identifies cryptochrome as a circadian photoreceptor in Drosophila. Cell. 1998;95:681-692.

19. Emery P, Stanewsky R, Hall JC, Rosbash M. A unique circadianrhythm photoreceptor. Nature. 2000;404:456-457. 
20. Whitmore D, Foulkes NS, Sassone-Corsi P. Light acts directly on organs and cells in culture to set the vertebrate circadian clock. Nature. 2000;404:87-91.

21. Cermakian N, Pando MP, Thompson CL, et al. Light induction of a vertebrate clock gene involves signaling through blue-light receptors and MAP kinases. Curr Biol. 2002;12:844-848.

22. Van Gelder RN, Wee R, Lee JA, Tu DC. Reduced pupillary light responses in mice lacking cryptochromes. Science. 2003;299:222.

23. Ebright JN, Bowes Rickman C. Rapid, reproducible real-time quantitative RT-PCR using the iCycler iQ real-time PCR detection system and iQ Supermix. Hercules, CA: Bio-Rad Corp.; 2003; technical note 2913.

24. Özgür S, Sancar A. Purification and properties of human blue-light photoreceptor cryptochrome 2. Biochemistry. 2003;42:2926-2932.

25. Jordan M, Schallhorn A, Wurm FM. Transfecting mammalian cells: optimization of critical parameters affecting calcium-phosphate precipitate formation. Nucleic Acids Res. 1996;24:596-601.
26. Petit C, Sancar A. La vie en bleu: des ADN photolyases aux photorecepteurs reglant les horloges biologiques. Med Sci. 1999;12: 1411-1418.

27. Kume K, Zylka MJ, Sriram S, et al. mCry1 and mCry 2 are essential components of the negative limb of the circadian clock feedback loop. Cell. 1999;98:193-205.

28. Thompson CL, Blaner WS, Van Gelder RN, et al. Preservation of light signaling to the suprachiasmatic nucleus in vitamin A-deficient mice. Proc Natl Acad Sci USA. 2001;98:11708-11713.

29. Van Gelder RN, Gibler TM, Tu D, et al. Pleiotropic effects of cryptochromes 1 and 2 on free-running and light-entrained murine circadian rhythms. J Neurogenetics. 2002;16:181-203.

30. Cahill GM, Besharse JC. Circadian clock functions localized in Xenopus retinal photoreceptors. Neuron. 1993;10:573-577.

31. Haque R, Chaurasia SS, Wessel JH III, Iuvone PM. Dual regulation of cryptochrome I mRNA expression in chicken retina by light and circadian oscillators. Neuroreport. 2002;13:2247-2251. 